\title{
Is Right Emotion with Creativity influences Academic Performance? A study of Emotional Intelligence, Creativity and Academic Achievements of Business Graduate Students
}

\author{
Kubilay Ozyer ${ }^{1}$, Muhammad Farooq $\mathrm{Jan}^{2}$, Farzand Ali Jan ${ }^{3}$, Asma Shabbir ${ }^{4}$ \\ ${ }^{1,2}$ Gaziosmanpaşa Üniversitesi, Tokat, Turkey, \\ ${ }^{3}$ COMSATS Institute of Information Technology, Attock, Pakistan, \\ ${ }^{4}$ COMSATS Institute of Information Technology, Islamabad, Pakistan,
}

\begin{abstract}
The study inclines to explore the effect of Emotional Intelligence and Creativity on academic achievement. A sample of 150 students has been taken to conduct the preliminary study. Three instruments were to gather data on Creativity, Emotional Intelligence and Academic achievements. The Multiple Regression, Pearson Product-Moment Correlation techniques and ANOVA test were used for analysis of data. Results of the study revealed that $E Q$ and creativity jointly predict the academic achievements of students however, when tested individually; EQ has positive significant relationship with CGPA, mean while creativity has positive insignificant relationship with CGPA. Additionally, no significant variances were found among the level of emotional intelligence and creativity of male and female student, while differences were found in the academic records of male and female students which tend to explain that female students had good grades than their male counterparts.
\end{abstract}

Keywords: Emotional Intelligence, Creativity, CGPA, Business Graduate Students, Academics.

\section{Introduction}

In the world of materialism, where everyone is running, the marathon to shine and come through the level of competition has changed to hyper aggressiveness. In such a dynamic competition, education is rope to success, greatness and brightening up life of an individual (Amusan, 2006). In a society different formal education systems prevails and in each, grades are important factor to judge the quality and standard of education which students are being imparted with, by the same education system. It is of high concern for educators to seek those factors which affect the academic performance of students, as it helps to distinguish high performers from low performers and also envisions the success of students at work in later stages of life (Onabamiroet al.,2007; Hassan, 2001). Many of the Formal Educational Institutes are endeavoring to produce students who are confident, hardworking, motivated and self- sufficient. Hence, the present study reflects to focus on Right Emotions with Creativity, influences Academic Performance by considering the relationship of Emotional Intelligence and creativity on academic achievements of Business Graduate students.

\section{Literature Review}

Mayer and Salovey, (1997) construed emotional intelligence as;

"the ability of one's person to understand his/her emotions, in order to access and to form emotions just to guide a thought process, to understand those emotions and knowledge of emotions, and to consciously control emotions so as to indorse intellectual and emotional growth".

Thus, emotional intelligence is the process of self-awareness and managing emotions to guide behaviors in right direction. According to Goleman, (1998) "Emotional intelligence is the capability of identifying our own and other's feelings, for observing ourselves, and for handling/dealing with our and other's emotions”. 
Therefore, it is non-cognitive ability to understand and manage own emotions and others to effectively regulate behaviors and relations. Akinboye, (2003) argued that to maintain success in one's own life and at workplace, one must have emotional intelligence which can be manifested in attributes like trust, loyalty, honesty, integrity, motivation, intuition, energy, courage, sensitivity, maturity and conscience. Ciarrochi et al, (2000) elucidated the significant positive correlation between different personality attributes of adolescents like empathy, self-esteem, openness to feeling, life satisfaction, extroversion, and verbal intelligence.

Emotional intelligence is an ability that can be learned, established and improved at any stage of life. If realized, one can improve his/her ability of managing and understanding emotions of self and others easily (Duckett, 2002). Emotional Intelligence has been probed intensely since long, particularly in relation to other psychological, occupational and social factors. For- example, Leban et al., (2004), found the success rate of emotionally intelligent leader is higher, as such leader is self-aware and mind full of follower's emotions, demands and wishes (McCarthy et al., 1999).

Studies of the past showed that individual academic achievements are based on Intelligent Quotient (IQ). It was strongly believed that good academic records are only based on conceptuality of mind that is more systematic and scientific (Douglas, 2006). Literature, for decades had been reminding us that individual's cognitive abilities are the true predictor of the success in profession and normal in daily life. It is dilemma of the Asians culture, that education systems are much focused on enhancing memorization and generalization. However, for now the Philosophy of Intelligence is changed from single dimension to Multiple Intelligences Theory (Gardner, 1983), Emotional Intelligence Theory (Goleman, 1995 and Mayer et al., 1999). After consistent efforts researchers found that success can not only be guaranteed by IQ but there are other intelligences that can help achieving our aims and making our path to success. With time, it has been realized that intelligence can have the following forms; analytical or mathematical intelligence, practical intelligence, creative intelligence, linguistic, musical, spatial, interpersonal, interpersonal, spiritual intelligence (Gardner, 1983).

The concern of the study is whether E.I and creativity are better predictor of success than I.Q. Focal point of many studies is that E.I and creativity assure success more than I.Q. Even, Goleman, (1995) defined 20\% portion of intelligence for IQ and the remaining $80 \%$ is justified by the other aspects of Intelligences. Here, a problem arises about the context and ambience of creativity and E.I i.e. how we can prescribe them, in what context these concepts will be used and how they influence academic achievements of students.

Creativity is defined as an ability of an individual to be unique, imaginative, generate or recognize ideas, alternatives and who produces some novel outcomes. Researcher suggested intelligence and creativity are the outcome of equivalent cognitive manner (O'Hara and Sternberg, 1999) and the relationship between them is much minor that we can treat them by separate approaches.

Creativity is about being imaginative, innovative, assertive, unique, confident, and independent and turning new ideas into reality. All said abilities are very much prerequisite for the enriched and fine life. Novelty and uniqueness brings new opportunities, modern concepts, advance ideas, latest designs that leads to innovation. A non-creative individual is locked-in around old patterns, structures, ideas, perceptions (Akinboye, 2003). Interest of study is centered on creativity and emotional intelligence influence on student's academic achievement as it has been observed that our education system is not providing any insight in innovative thinking and valuation procedures do not reward innovation and creativity.

Creativity and emotions are impressively related as it boasts energy and power of the person, that's why an artist always need an emotional state to show his /her artistic masterpiece (Akinboye, 2003). Psychological studies revealed that an emotionally intelligence person has ability to manage and regulate his/her emotions, mind free of destructive thoughts, remains calm and relax, makes room for new ideas and creative than a person whose E.I level is low (Goleman, 1998). Van Der Zee et al., (2002) asserted that no significant association between academic performance and E.I and if there is any claim regarding the possible association between the two, then the study would be followed in a detailed perspective. 
In the view of above stated account, the present study is focused on analyzing and exploring the relative and mutual influence of creativity and E.I on the academic achievements of Graduate students of COMSATS Institute of Information Technology, Islamabad.to (please specify).

\section{Hypothesis Development}

The study is based on following hypothesis;

Hypothesis 1: Emotional Intelligence and Creativity compositely affect the level of academic records of students.

Hypothesis 2: Emotional Intelligence effect the level of students' academic records.

Hypothesis 3: Creativity effect the level of student's academic records.

Hypothesis 4: The nature of relationship between business students' CGPA and their relative EQ and Creativity.

Hypothesis 5: Difference in level of emotional intelligence, creativity and academic achievements of male and female Graduate student?

\section{Methodology}

\subsection{Participants}

The data was collected from the Business Administrative students of COMSATS Institute of Information Technology, Islamabad. The potential population includes all the students of Bachelors in Business Administration and Master in Business. A sample of 150 students including 80 students from the program; Bachelors in Business Administration and remaining 70 students were chosen from Master in Business Administration program including 65 females and 85 male students. The small sample size based on the availability and the number of students registered for those specific programs.

\subsection{Instruments}

Survey technique was used for collecting data through Self administrated questionnaire. Under mentioned three types of instruments were used to collect data on respective variables of EQ, creativity and CGPA (Student Cumulative Grade Point) as an indicator of academic achievement;

1.CGPA Information Format (Olatoye et al., 2010),

2.Wong and Law Emotional Intelligence scale (WLEIS), (Law and Wong, 2002)

3.Nicolas Holt Creativity Test (NHCT), (Halt, ????????????)

\subsection{Procedure}

A formal permission were taken from the Head of Department of Management Sciences and Examination office, data related to CGPA was accessed and obtained in SCIF format, as mentioned above. Based on convenience sampling technique, the questionnaires were handed using two ways; firstly personally handed to individual students and taken back the filled one; secondly in order to consider the prominence of regular lectures, the questionnaire was handed to the class representative and then collected back. Commonly, the time span between distributing and collecting the questionnaire takes a week. The participation of the students was entirely voluntary and the calculated response rate was $87.14 \%$, which is reflected a good response rate.

\subsection{Reliability Analysis}

The reliability analysis was checked through Cronbach alpha values, depicting the values are higher than 0.7 , displayinga good consistency among items. Total 29 items were consideredand the alpha score is 0.937 for creativity, while 16 items were considered for emotional intelligence and the alpha score is 0.894 . The range of a lie between $0.7 \leqslant a<0.9$, depicting a good relationship. Table 2 describes reliability of variables. 
TABLE 1: Reliability Score of Variables

\begin{tabular}{lcc}
\hline Variables & $\begin{array}{c}\text { No. of } \\
\text { Items }\end{array}$ & $\begin{array}{c}\text { Cronbach } \\
\text { Alpha }\end{array}$ \\
\hline Emotional Intelligence & 16 & 0.894 \\
Creativity (NHCT) & 29 & 0.937 \\
\hline
\end{tabular}

\subsection{Correlation Analysis}

The relationship between the variables was checked through correlation analysis. This analysis depicts the association/ connection among variables. The correlation between creativity and emotional intelligence $(\mathrm{r}=0.473$, $\mathrm{p}<0.01$ ), emotional intelligence and student academic records $(\mathrm{r}=0.467, \mathrm{p}<0.01)$ and creativity and student academic record $(\mathrm{r}=0.321, \mathrm{p}<0.01)$. All variables show positive relationship them. A strong relationship found between emotional intelligence and student academic records found $(r=0.467)$, while weak relationship found between creativity and student academic record ( $\mathrm{r}=0.321)$.

The correlation analysis also provides the justification of hypothesis which states that nature of relationship between business students' CGPA and their relative EQ and Creativity. Table 1 describe correlation among variables.

TABLE 2: Correlation Matrix of Variables

\begin{tabular}{|c|c|c|c|c|}
\hline S. No & Variables & 1 & 2 & 3 \\
\hline 1 & Emot. Int. & 1.00 & & \\
\hline 2 & Creativity & $0.473 * *$ & 1.00 & \\
\hline 3 & $\begin{array}{c}\text { Student Aca. } \\
\text { Ach. }\end{array}$ & $0.467 * *$ & $0,321^{* *}$ & 1.00 \\
\hline
\end{tabular}

Note: ** Correlation is significant at the 0.01 level (2-tailed)

\subsection{Regression Analysis}

Regression analysis was performed to test the hypothesis. The combined effect of Emotional intelligence and creativity on the level of academic records of students was tested and results show that the EI and creativity account for $28.5 \%$ variations in students' academic records. Overall the relationship is significant at ( $\mathrm{F}=32.717$, $\mathrm{P}<0.001)$. In the nutshell, results hypothesizeemotional intelligence and creativityhave a compound effect on the level of academic records of students and are relevant in estimating and improving the academic achievements of business graduate students. Further description is given in table 3.

TABLE 3: Combined Effect of Emotional Intelligence and Creativity on Student Academic Achievements

\begin{tabular}{|l|l|l|}
\hline \multirow{2}{*}{\multicolumn{1}{|c|}{ Variables }} & \multicolumn{2}{c|}{ Student Academic Achievement } \\
\cline { 2 - 3 } & \multicolumn{1}{|c|}{$\beta$} & \multicolumn{1}{c|}{ t-value } \\
\hline Emot. Int. & $0,253^{* * *}$ & 4,326 \\
\hline Creativity & $0,172 * *$ & 2,573 \\
\hline F & $32.717 * * *$ & \\
\hline R2 & 0,285 & \\
\hline Adjusted R2 & 0,275 & \\
\hline
\end{tabular}

Note: $* * *$ p<0.001; IV: EI and Creativity, DV: Student Academic Records

The effect of emotional intelligence and the level of students' academic records was tested and result indicates that $23.4 \%$ variations in the level of academic achievements is being explained by emotional intelligence. Emotional intelligence has a significant positive effect on academic achievements of business graduates $(\beta=0.268, \mathrm{P}<0.001)$, also depicting an important factor in the level of academic records of student $(\mathrm{t}=4.786)$. Overall model is significant at $(\mathrm{F}=31.456, \mathrm{p}<0.001)$. Hence, results summarised that students having emotionally intelligence tendency tends to get extraordinary grades/ records in their academic performance.

On the other side, the effect of creativity on academic records of the students was tested and summarised that $26.9 \%$ variations in the level of academic achievements is being explained by creativity. Creativity has a positive but insignificant effect on academic achievements of students $(\beta=0.178, \mathrm{P}>0.05)$. Creativity shows less important factor in achieving good academic records $(\mathrm{t}=2.765)$ while model is significant at $(\mathrm{F}=30.976$, $\mathrm{P}>0.001)$. Further details are mentioned in table 4 
TABLE 4:Discrete Effect of Emotional Intelligence and Creativity on Student Academic Achievements

\begin{tabular}{|c|c|c|c|c|}
\hline \multirow[t]{2}{*}{ Variables } & \multicolumn{2}{|c|}{ Emotional Intelligence } & \multicolumn{2}{|c|}{ Creativity } \\
\hline & $\beta$ & t-value & $\beta$ & t-value \\
\hline $\begin{array}{l}\text { Stud. Aca. } \\
\text { Ach. }\end{array}$ & $0,268 * * *$ & 4.786 & 0,178 & 2,765 \\
\hline $\mathrm{F}$ & \multicolumn{2}{|c|}{$31.456 * * *$} & \multicolumn{2}{|c|}{30.967} \\
\hline $\mathrm{R} 2$ & \multicolumn{2}{|c|}{0.234} & \multicolumn{2}{|c|}{0.269} \\
\hline Adjusted R2 & \multicolumn{2}{|c|}{0.246} & \multicolumn{2}{|c|}{0.464} \\
\hline $\begin{array}{l}\text { Durbin- } \\
\text { Watson }\end{array}$ & \multicolumn{2}{|c|}{1.675} & \multicolumn{2}{|c|}{1.121} \\
\hline
\end{tabular}

Note: $* * * \mathrm{p}<0.001$; IV: EI and Creativity, DV: Student Academic Records

\section{Discussion}

The current study was based on the relationship between emotional intelligence, creativity and academic records of students. The study identified positive significant relationship between emotional intelligence and creativity of the business graduates students, suggesting a person with emotional intelligence tendsto be creative and the outcomes are aligned withTatlah et al., (2012); Olatoye et al., (2010). In fact, Davdar, (2012) postulated EQ components can predict the amount of creativity in students. The second finding of the study established a positive significant relationship between the EQ and Academic Achievement of business graduate students, which contradicts the study of Nelson and Low (2003); Tatlah et al., (2012); Petrides et al., (2004).

Elias et al., (2006) suggested a positive association between EQ and Academic performance when social and emotional skills are taught at school. Emotional skills andlearning are very much essential for effective performance not only in school/university but in professional stages of life. Since emotional intelligence is expected to promote student's ability and capacity to deal with academic demands, one may doubt the mode of measuring technique of academic achievement as less encouraging in creative thinking. Here, the study entails positive insignificant association between creativity and academic achievement of business student, i.e. a creative student may not have academic gain over the less creative one, which in lines with the outcomes of Tatlah et al., (2012) but contradicts with the outcomes of Anwar, (2012). This possibility is supported by the studies of Bentley (1966), highlighted that majority of the academic examinations are testing the memory based skills and cognitive abilities of students rather than creative ones, therefore it can be concluded that highly creative students can be unjustifiably penalized with low grades. Similarly Xiaoxia, (1999) also posited rare association of creativity and academic achievement.

In Pakistan's context, bundle of other factors may contributes inthe academic achievement, most worthy to consider is the parental preferences and teaching practices. The stress of getting grades inhibits the creative ability of mind. Moreover, examination system is based on cognition and memory testing. This points toward a review of curriculum, teaching style of tutors and evaluation of performance in line with the need of emotional intelligent and creativity as tool for encouraging healthy mind in making ventures and to be an entrepreneurs.

Moreover, the evaluation and estimation of student's creativity and intelligence cannot be judged by CGPA alone. Secondly the extra burden of academic assignments in semester system has also restricted students to engage in some creative and non- curriculum activities leading to inept social graces and incompetent character. Students, the future entrepreneurs, are lagging behind on social and creative aspects of learning due of the inadequate academic and ingenious skills embodied by bottomed out education system of Pakistan.

Based on the results of study, it is suggested that emotional intelligence and creativity should be well taught as separate courses in academia. The curriculum should be dynamic and progressive. There must be equality and quality in it and special monitoring and evaluation system should be introduced by higher education bodies. The faculty should be professionally qualified and trained to teach creative and academic skills particularly at early schooling so the students when enter in universities, could outshine and outperform. Teacher-student collaboration must be well established via extra coaching classes to explore the interests and questions of students that will express their learning and development of mind and morale. 


\section{References}

[1] Akinboye, J.O. (2003). Creativity, Innovation and success. Ibadan: Sterling Horden Publisher (Nig) Ltd.

[2] Amusan, O.(2006).Teacher and Universal Basic Education: Ogun Update, Bi-monthly Newsletter of Ogun State Public Service, 5(8).

[3] Anwar, .N. M. (2012). Relationship of Creative Thinking with Academic Achievements of secondary School Students. International Interdisciplinary Journal of Education, 1(3), 12-24.

[4] Ciarrochi, J. V., Chan, A. Y., \& Caputi, P. (2000). A critical evaluation of the emotional intelligence construct. Personality and Individual differences, 28(3), 539-561.

https://doi.org/10.1016/S0191-8869(99)00119-1

[5] Douglas, K.D. (2006). Intelligence Microsoft @ Encarta; 1993-2005 Microsoft Corp.

[6] Duckett, M. (2002). General intelligence, average intelligence and emotional intelligence. Handbook of Human Intelligence, New York: Cambridge University Press.

[7] Elias, M. J. (2006). The connection between academic and social-emotional learning. The educator's guide to emotional intelligence and academic achievement, 4-14.

[8] Gardner, W.L. (1983). The psychology of teaching. Monterey: CA Books/Cole. https://doi.org/10.1207/s15328023top1001_5

[9] Goleman, D. (1995). Emotional Intelligence. Why it can matter no than I.Q. London, Bloomsberg.

[10] Goleman, D. (1998). What makes a Leader? (HBR, Nov/Dec 1998 pg 33) USA.

[11] Hassan, T. (2001). Students' Performance and Certification. Paper in proceeding of the 10th Annual Congress of Nigerian Academy of Education held in the University of Jos, 12-16 Nov, 2001.

[12] Law, K.S. \& Wong, C. (2002). The Construct and Criterion Validity of Emotional Intelligence and it potential utility for Management Studies. Journal of Applied Psychology, 89(3), 483-496.

https://doi.org/10.1037/0021-9010.89.3.483

[13] Leban, W., \& Zulauf, C. (2004). Linking emotional intelligence abilities and transformational leadership styles. Leadership \& Organization Development Journal, 25(7), 554 - 564.

https://doi.org/10.1108/01437730410561440

[14] Mayer, J., Caruso, D. \& Salovey, P. (1999). Emotional Intelligence meets Traditional standard for intelligence. Intelligence, 27(1), 19-21.

https://doi.org/10.1016/S0160-2896(99)00016-1

[15] McCarthy, A.M., \& Garavan, T. M. (1999) Developing self-awareness in the managerial career development process: the value of 360-degree feedback and the MBTI. Journal of European Industrial Training, 2(9), $437-445$. https://doi.org/10.1108/03090599910302613

[16] Nelson, D., \& Low, G. (2003). Emotional Intelligence: Achieving Academic and Career Excellence. Upper Saddle River, NJ: Prentice Hall.

[17] O'Hara, L.A. \& Sternberg, R.J. (1999). Creativity and Intelligence. In E.D Sternberg, R.J. (Eds) Handbooks of Creativity, Cambridge: Cambridge University Press.

[18] Olatoye, R. A., Akintunde, S. O., \& Yakasai, M. I. (2010). Emotional Intelligence, Creativity and Academic Achievement of Business Administration Students. Electronic Journal of Research in Educational Psychology, 8(2).

[19] Onabamiro, A., Owoyele, J., Toyobo, W., \& Majekodumi, O. (2007). Some Causative Factors as Correlates of Studentse Academic Achievement in two Secondary School Core Subjects in Four State Capitals in Nigeria: Implication for Counseling. Journal of Applied Education and Vocational Research, 2(3), 45-52. 
[20] Petrides, K. V., Frederickson, N., \& Furnham, A. (2004). The role of trait emotional intelligence in academic performance and deviant behavior at school. Personality and individual differences, 36(2), 277-293. https://doi.org/10.1016/S0191-8869(03)00084-9

[21] Tatlah, I. A., Aslam, T. M., Ali, Z., \& Iqbal, M. (2012). Role of intelligence and creativity in the academic achievement of students. International Journal of Physical and Social Sciences, 2(7), 1-10.

[22] Van der Zee, K., Thijs, M., \& Schakel, L. (2002). The relationship of emotional intelligence with academic intelligence and the Big Five. European journal of personality, 16(2), 103-125. https://doi.org/10.1002/per.434

[23] Xiaoxia, A.I. (1999). Creativity and Academic Achievement: An investigation of Gender Differences. Mahwah: Mahwah Publishers. 